\title{
Human Mixed Infections of Leishmania spp. and Leishmania- Trypanosoma cruzi in a Sub Andean Bolivian Area: Identification by Polymerase Chain Reaction/hybridization and Isoenzyme
}

\author{
B Bastrenta/ ${ }^{+}$, N Mita*, R Buitrago*, F Vargas*, M Flores*, M Machane*, N Yacsik*, \\ $M$ Torrez $^{*}$, F Le Pont ${ }^{* *}$, F Brenière***
}

UMR CNRS/IRD no 9926 "Génétique Moléculaire des Parasites et des Vecteurs” **IRD Laboratoire d'Entomologie, Mission La

Paz, CP 9214 La Paz, Bolivia *Universidad Mayor San Andrès, Instituto Boliviano de Biología de Altura, La Paz, Bolivia ***Institut de Recherche pour le Développement UR 008, Pathogénie des Trypanosomatidés, Montpellier, France

Parasites belonging to Leishmania braziliensis, Leishmania donovani, Leishmania mexicana complexes and Trypanosoma cruzi (clones 20 and 39) were searched in blood, lesions and strains collected from 28 patients with active cutaneous leishmaniasis and one patient with visceral leishmaniasis. PCR-hybridization with specific probes of Leishmania complexes (L. braziliensis, L. donovani and L. mexicana) and T. cruzi clones was applied to the different DNA samples. Over 29 patients, 8 (27.6\%) presented a mixed infection Leishmania complex species, 17 (58.6\%) a mixed infection Leishmania-T. cruzi, and $4(13.8 \%)$ a multi Leishmania-T. cruzi infection. Several patients were infected by the two Bolivian major clones 20 and 39 of T. cruzi (44.8\%). The L. braziliensis complex was more frequently detected in lesions than in blood and a reverse result was observed for L. mexicana complex. The polymerase chain reaction-hybridization design offers new arguments supporting the idea of an underestimated rate of visceral leishmanisis in Bolivia. Parasites were isolated by culture from the blood of two patients and lesions of 10 patients. The UPGMA (unweighted pair-group method with arithmetic averages) dendrogram computed from Jaccard's distances obtained from 11 isoenzyme loci data confirmed the presence of the three Leishmania complexes and undoubtedly identified human infections by L. (V.) braziliensis, L. (L.) chagasi and L. (L.) mexicana species. Additional evidence of parasite mixtures was visualized through mixed isoenzyme profiles, L. (V.) braziliensis-L. (L.) mexicana and Leishmania spp.-T. cruzi. The epidemiological profile in the studied area appeared more complex than currently known. This is the first report of parasitological evidence of Bolivian patients with trypanosomatidae multi infections and consequences on the diseases' control and patient treatments are discussed.

Key words: leishmaniasis - Chagas disease - mixed infection - isoenzyme characterization - polymerase chain reaction

Among Latin American countries, Bolivia suffers from the highest infection rates of Chagas disease cases with a sero prevalence of $40 \%$ (Bryan \& Tonn 1990), which represents a significant cause of morbidity and mortality (WHO 1991) for the country. More than 3 million people live in endemic regions and indicators of sero positivity infection reach 75\% in several areas (Pless et al. 1992). The National Control Program considers Chagas disease in the Yungas valleys, a Sub-Andean region localized in the La Paz department, as non-endemic. However, vectors (Triatoma infestans) have been found in many houses (Le Pont et al. 1992, Brenière et al. 1995) and a recent epidemiological survey detected $12.7 \%$ seroprevalence for T. cruzi infection in the North Yungas province (unpublished data).

\footnotetext{
This work received financial support from, UNDP/World Bank Special Program for Research and Training in Tropical Diseases, (Tegumentary leishmaniasis: risk factors and self-protection no. 940902) and from IRD (Institut de Recherche pour le Développement).

${ }^{+}$Corresponding author. Fax: 591(2) 27829 44. E-mail: Bastrenta@mail.megalink.com

Received 18 June 2002

Accepted 4 December 2002
}

Leishmaniasis in Bolivia is less frequent than Chagas disease, however this disease affects people in five out of nine Bolivian departments. In the "Yungas" valleys cutaneous and mucocutaneous leishmaniasis constitute a serious public health issue, since consequences for the infected patients are severe mutilations, mostly located on their face (Le Pont et al. 1992). In this area, a prevalence of around 20\% was reported based on observation of active lesions and scar without differences according to sex (Le Pont et al. 1992). In this focus cutaneous and muco-cutaneous leishmaniasis are due to Leishmania (Viannia) braziliensis (Desjeux et al. 1974). In North and South Yungas provinces (corresponding to the studied area) 353 cases of cutaneous and muco-cutaneous leishmaniasis have been registered in 2001 (report of the SNIS, Ministerio de Salud, Bolivia). Whereas parasites belonging to Leishmania (Leishmania) amazonensis were scarcely identified (Desjeux et al. 1987, Le Pont et al. 1992, Dedet 1993), a recent study had revealed a new restricted focus due to $L$. (L.) amazonensis (Martinez et al. 1998) in a Yungas valley characterized by a severe dry season. The strain of the first case of human visceral leishmaniasis was identified without a doubt by isoenzyme as Leishmania (L.) chagasi (Desjeux et al. 1986). Up to now, six autochthonous case of visceral leishmaniasis have been reported in Bolivia (Dimier-David et al. 1991) but the incidence of this infection and the morbidity are unknown. 
Recently, patient infection caused by Leishmania (V.) lainsoni has been described (Martinez et al. 2001, Bastrenta et al. 2002).

As in many region of South America, in the Yungas valleys there are overlapping endemic areas for Chagas disease and leishmaniasis. The occurrence of leishmaniasis patients carrying a double infection with $T$. cruzi has been shown by serological specific tests in various works and more scarcely by parasitological methods (Lemesre et al. 1986, Chiller et al. 1990, Chiaramonte et al. 1996). Moreover few cases of simultaneous infections with different Leishmania species have been reported by characterization of isolated stocks in the New World (Silveira et al. 1984, Oliveira Neto et al. 1985, Hernandez-Montes et al. 1998).

The purpose of this work is to identify patients carrying a double infection of Leishmania spp. and Leishmania-T. cruzi by a direct identification of parasites in blood and lesions of patients with active leishmaniasis. The different Leishmania species and the major Bolivian clones of T. cruzi were detected by the PCR amplification of the variable regions of the kinetoplast followed by the hybridization of the PCR products with specific probes of Leishmania complex (L. mexicana, L. donovani and $L$. braziliensis) and specific probes of $T$. cruzi clones 20 and 39 (numbering according to Tibayrenc et al. 1986). Mixed infections were also demonstrated by isoenzyme characterization of the parasites isolated from the patients. The epidemiological consequences due to this new data and further implications are discussed.

\section{PATIENTS AND METHODS}

Origin of the studied patients - Patients came from South (16 $\left.24^{\prime} \mathrm{S}, 67^{\circ} 31^{\prime} \mathrm{W}\right)$ and North $\left(16^{\circ} 15^{\prime} \mathrm{S}, 67^{\circ} 40^{\prime} \mathrm{W}\right)$ Yungas in the department of La Paz, Bolivia. The Yungas are steep-sided valleys in the Eastern Andean Cordillera, at an altitude ranging from $1000-1800 \mathrm{~m}$ a.s.l. characterized by a subtropical climate. The 29 studied patients were received at the hospital for medical attention concerning typical lesions of leishmaniasis infections (28 cases) and visceral leishmaniasis in one two-year old patient. Moreover, mucosal lesions were suspected in two patients by the presence of nasal blockage and perforation. Leishmaniasis diagnosis was based on clinical observations, epidemiological history and positivity of Giemsa-stained smear of dermal scrapings (11 cases).

Biological samples - For the 29 patients, $5 \mathrm{ml}$ of venous blood were collected, $1 \mathrm{ml}$ of which was mixed immediately with an equal volume of $6 \mathrm{M}$ guanidine $\mathrm{HCl} / 0.2 \mathrm{M}$ EDTA, pH 8 for further PCR processing. Some drops of blood were added in two cultures tubes of NNN biphasic medium supplemented with $1.5 \mathrm{ml}$ of Schneider medium and serum was separated from the remaining $4 \mathrm{ml}$ for further serologic tests.

Two fine-needle aspirates were taken from cutaneous ulcers with a $3 \mathrm{ml}$ syringe containing $0.5 \mathrm{ml}$ of sterile normal saline solution. One of the samples was conserved in nitrogen for PCR processing and the other one was distributed in two culture tubes.

A bone-marrow puncture was accomplished on the child with visceral leishmaniasis to process PCR and culture.
An oral consent was obtained from the patients and parents for the biological sampling.

Parasite isolation in culture - At the laboratory, some drops of heated inactivated foetal calf serum were added to each culture tube and they were incubated at $32^{\circ} \mathrm{C}$. Culture were examined daily until their adaptation. Subcultures were realized in Schneider's medium supplemented with $20 \%$ heat-inactivated foetal serum. Promastigotes were grown at $25^{\circ} \mathrm{C}$.

Isoenzyme characterization - The conditions for electrophoresis on cellulose acetate plates (Helena) were carried out according to Ben Abderrazak et al. (1993). A total of 10 enzyme systems (11 loci) were performed: glucose phosphate isomerase (GPI, EC 5.3.1.9), glucose-6-phosphate dehydrogenase (G6PD, EC 1.1.1.49), isocitrate dehydrogenase (IDH, EC 1.1.1.42), malate dehydrogenase NAD+ (MDH, EC 1.1.1.37), malate dehydrogenase NADP+ or malic enzyme (ME, EC 1.1.1.40), peptidase 1, substrate L-Leucyl-leucine-leucine (Pep-1, EC 3.4.11) phosphoglucomutase (PGM, EC 2.7.5.1), 6-phospho-gluconate dehydrogenase (6PGD, EC 1.1.1.44), glutamate dehydrogenase NADP+ (GDH-NADP+, EC 1.4.1.4), glutamate dehydrogenase NAD+ (GDH-NAD+, EC 1.4.1.2) and glutamate oxaloacetate transaminase (GOT, EC 2.6.1.1).

The following reference stocks were used: $L$. (L.) mexicana (MNYC/BZ/M379), L. (L.) chagasi (MHOM/ BR/74/PP75), L. (V.) braziliensis (MHOM/BO/84/LPZ595) and T. cruzi (clone 39: $\mathrm{MN}$ and clone 20: $\mathrm{SO} 34 \mathrm{cl} 4$ ).

Phenetic clustering of the isolates - Phenetic relationships among the isolates and the reference stocks were inferred by computing Jaccard's distance (Jaccard 1908). The UPGMA method, (unweighted pair-group method with arithmetic averages) was used for the construction of the dendrogram showing the relationship among the stocks (Sokal \& Sneath 1963). The dendrogram was obtained using the NTSYS software (Exeter, Setauket, NY, USA).

Serological techniques - The detection by immunofluorescence of specific antibodies against $L$. (V.) braziliensis (MHOM/BR/75/M2903) was carried out according to Camargo (1966) using promastigotes forms fixed by $2.5 \%$ glutaraldehyde. Sera were assayed in serial two-fold dilutions from 1/30. The fluorescein isothiocyanate (FITC)-conjugate anti-human IgM (Sigma-Aldrich, St Louis, USA) diluted 1:50 (according to the manufacturer) in PBS containing $0.01 \%$ of Evans blue was used as second antibody.

Specific anti-T. cruzi IgG were detected by enzymelinked immunosorbent assay (ELISA) using a crude antigen obtained from epimastigotes culture forms (Tehuantepec strain), according to previous studies (Brenière et al. 1985). The sera were diluted $1 / 200$. The sheep peroxidase-conjugate anti-human IgG (H-L) (Biosys, Compiène, France) was used at a dilution of 1/ 2500.

DNA extraction and PCR conditions - The method used to treat the samples prior to PCR amplification has been previously described (Britto et al. 1993) and DNA extraction was performed as described by Wincker et al. (1994). 
The Leishmania kDNA-PCR procedure was performed in duplicate in blood, lesions samples and parasite culture, according to Brenière et al. (1999) with primers L1: 5'CCT ACC CAG AGG CCT GTC GGG-3' and L2: 5' -TAA TAT AGT GGG CCG CGC AC-3', purchased from Eurogentec laboratory (Seraing, Belgium).

PCR detection of T. cruzi in blood samples and parasite culture, was performed in duplicate according to Brenière et al. (1998), using the following primers: 121: 5' AAA TAA TGT ACG G (T/G) GAG ATG CAT GA-3' and 122: 5'-GGG TTC GAT TGG GGT TGG TGT-3', purchased from Eurogentec laboratory.

Each run included positive and negative controls using parasite purified DNA and DNA free water as template respectively. PCR products were analysed by electrophoresis on $0.8 \%$ agarose gels in TAE X 0.5 and visualised by ethidium bromide staining.

Probes - Five kDNA reference probes were used. The three Leishmania complex-specific probes, L. (L.) mexicana (MNYC/BZ/M379), L. (L.) chagasi (MHOM/ BR/74/PP75), L. (V.) braziliensis (MHOM/BO/90/CG), were produced by PCR according to Brenière et al. (1999) using L1 and L2 primers, and T. cruzi specific probes of clone 39 and clone 20 were produced according to Brenière et al. (1998) using CV1 and CV2 primers (CV1: 5' GAT TGG GGT TGG AGT ACT AT 3' and CV2: 5' TTG AAC GGC CCT CCG AAA AC 3') and DNA extracts of the reference stocks, TPKI (clone 39) and SO34 cl4 (clone 20). The amount of DNA was quantified by electrophoresis of sequential dilutions.

Labelling and hybridization conditions - After nylon membrane transfert of PCR products, labelling probes and hybridization were processed with the enhanced chemiluminescence gene detection system (ECL Amersham, Buckinghamshire, UK) according to the manufacturer's instructions. The membranes were washed twice under highly stringent conditions $(6 \mathrm{M}$ urea, $0.1 \mathrm{x}$ $\mathrm{SSC}$ at $42^{\circ} \mathrm{C}$ for $20 \mathrm{~min}$ ) and then twice in $2 \mathrm{x} \mathrm{SSC}$ at room temperature for $10 \mathrm{~min}$. Three exposures were performed (1, 5 and $30 \mathrm{~min}$ ) on Hyperfilm-MP (Amersham, Buckinghamshire, UK).

\section{RESULTS}

The Table resumes the results obtained for each analysis: microscopically examination of lesion aspirates (Smear), origin of culture, isoenzyme typing, PCR/hybridization from isolated stains, blood and lesion aspirates and serology. The whole analysis confirmed Leishmania spp. infections for the 29 studied patients. Microscopically examination of lesion aspirates showed positivity in 11 cases (25 examined). Isoenzyme typing and PCR hybridization allowed the identification of the different Leishmania spp. and the detection of $T$. cruzi concurrent infections in several cases.

Species characterization of the strains - Twelve parasite strains were successfully isolated from the blood of two patients $(6.9 \%)$, lesions of nine patients $(31 \%)$ and one strain from the bone-marrow of the child diagnosed with visceral leishmaniasis. Four strains (Chu 02, Chu 04, Lp 06, Lp 07) shown complex patterns for several enzyme systems suggesting mixed infections (Table) and part of these patterns are illustrated in Fig. 1: 6PGD, (Lp 07, $L$. (L.) mexicana and $L$. (V.) braziliensis, PGM, (Lp 06, L. (V.) braziliensis and T. cruzi clone 39), ME-1, (Chu 02, L. (L.) mexicana and T. cruzi clone 20), and GDH-1, (Chu 04, T. cruzi clones 20 and 39). The dendrogram (Fig. 2) computed from MLEE Jaccard's distance was established with the other eight strains, which did not show mixture profiles. The dendrogram clustered one strain isolated from a lesion (Lp 02) with $L$. (L.) mexicana, the strain isolated from the bone-marrow (Lp 17) with $L$. (L.) chagasi, and the six other strains isolated from lesions with $L$. $(V$.) braziliensis. PCR/hybridization applied to the strain cultures provided us confirmation of species and mixtures observed by isoenzymes analysis. Furthermore, PCR/hybridization evidenced the presence of $T$. cruzi in 10 of the 12 strains and one additional mixture of $L$. (V.) braziliensis and $L$. (L.) mexicana (Lp 16, Table).

The current analysis of the strains evidences the occurrence of the three Leishmania complexes (L. donovani, L. braziliensis and L. mexicana) in the studied area as well as co-infections with $T$. cruzi.

Detection of Leishmania spp. and T. cruzi from blood and aspirate samples by PCR-hybridization - PCR-hybridization was applied on blood and aspirate lesion samples of the 29 patients using the five specific probes to identify Leishmania complexes and major clones 20 and 39 of T. cruzi. A typical result for a series of PCR tests is shown in Fig. 3a. Using L1-L2 primers, multi-sized products ranging from $100 \mathrm{bp}$ to $1300 \mathrm{bp}$ and characteristic of Leishmania spp. were amplified and with 121-122 primers
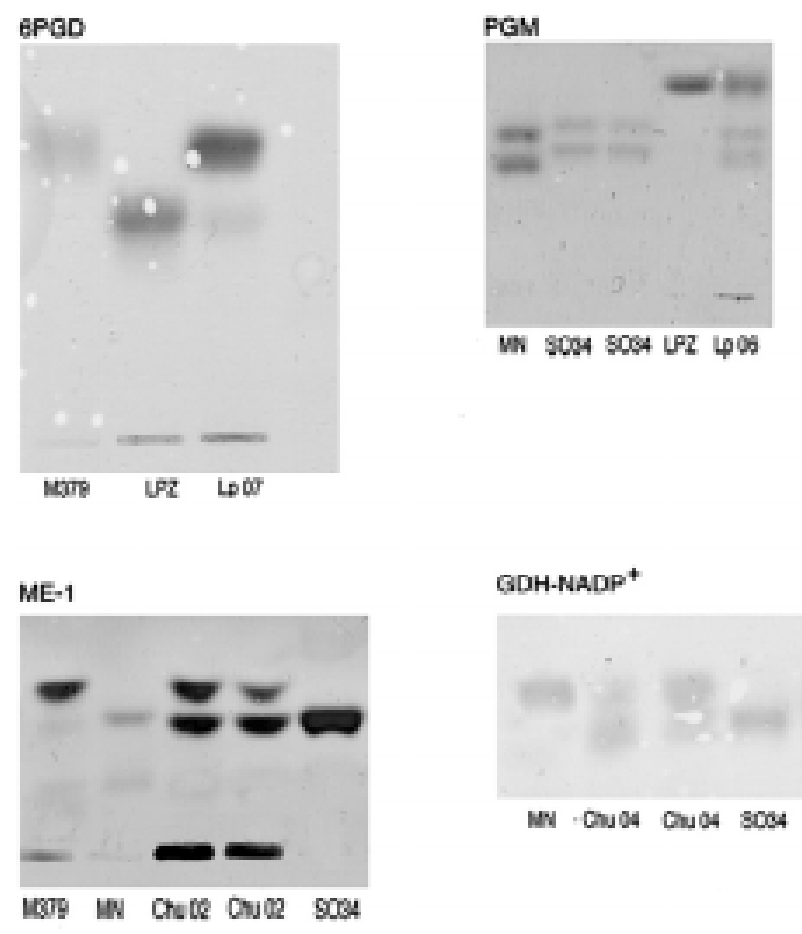

Fig 1: isoenzyme profiles of strains isolated from lesions (Lp 07, Lp 06) and blood (Chu 02 and Chu 04) evidencing mixtures of species: Leishmania. (L.) mexicana (M379)-L. (V.) braziliensis (LPZ) with 6PGD enzyme; L. (V.) braziliensis (LPZ)-Trypanosoma cruzi clone 20 (SO34 cl4) with PGM enzyme; $L$. (L.) mexicana (M379)-T. cruzi clone 39 (MN) with ME-1 enzyme; T. cruzi clone 20 (SO34 c14) and 39 (MN) with GDH- NAPD+ enzyme 
TABLE

Isoenzyme characterization and polymerase chain reaction/hybridization detection of Trypanosoma cruzi and Leishmania spp. Leishmaniasis and Chagas sero-diagnosis, applied to 29 leishmaniasis patients from the department of La Paz, Bolivia

\begin{tabular}{|c|c|c|c|c|c|c|c|c|c|}
\hline \multirow[b]{2}{*}{$\begin{array}{l}\text { Patient } \\
\text { code }\end{array}$} & \multirow[b]{2}{*}{ Smear } & \multirow[b]{2}{*}{$\begin{array}{l}\text { Strain } \\
\text { Origin }\end{array}$} & \multirow[b]{2}{*}{ Isoenzyme typing } & \multirow{2}{*}{$\begin{array}{c}\text { Culture } \\
\text { PCR-hybridization } \\
\text { with Leishmania complex } \\
\text { and T. cruzi probes }\end{array}$} & \multicolumn{2}{|c|}{ Blood } & \multirow{2}{*}{$\begin{array}{c}\text { Lesions } \\
\text { PCR-hybridization } \\
\text { with Leishmania } \\
\text { complex probes }\end{array}$} & \multicolumn{2}{|c|}{ Serological data } \\
\hline & & & & & $\begin{array}{l}\text { PCR-hybridization } \\
\text { with Leishmania } \\
\text { complex probes }\end{array}$ & $\begin{array}{l}\text { PCR-hybridization } \\
\text { with } T \text {. cruzi probes } \\
\text { (clones } 20 \text { and } 39 \text { ) }\end{array}$ & & $\begin{array}{c}\text { IF } \\
\text { Leishmania }\end{array}$ & $\begin{array}{l}\text { ELISA } \\
\text { T. cruzi }\end{array}$ \\
\hline Lp 26 & nd & Lesion & L. (V.) braziliensis & $\mathrm{Lb}$ & Hyb. (-) & 39 & $\mathrm{Lb}$ & nd & - \\
\hline Lp 10 & + & Lesion & L. (V.) braziliensis & $\mathrm{Lb}$ & Hyb. (-) & $20+39$ & $\mathrm{Lb}$ & + & - \\
\hline Lp 15 & + & Lesion & L. (V.) braziliensis & Lb, Tc cl 39 & Hyb. (-) & 39 & $\mathrm{Lb}$ & nd & nd \\
\hline $\mathrm{Lp} 45$ & + & Lesion & L. (V.) braziliensis & $\mathrm{Lb}, \mathrm{Tc} \mathrm{cl} 20+39$ & Hyb. (-) & $20+39$ & $\mathrm{Lb}$ & + & - \\
\hline Lp 46 & + & Lesion & L. (V.) braziliensis & $\mathrm{Lb}, \mathrm{Tc} \mathrm{cl} 20+39$ & Hyb. (-) & PCR (-) & $\mathrm{Lb}, \mathrm{Lm}$ & - & nd \\
\hline Lp 16 & + & Lesion & L. (V.) braziliensis & $\mathrm{Lb}, \mathrm{Lm}, \mathrm{Tc}$ other clone ${ }^{a}$ & $\mathrm{Lm}$ & $20+39$ & $\mathrm{Lb}$ & - & nd \\
\hline Lp 17 & + & Bone-marrow & L. (L.) chagasi & Ld, Tc cl 20 & $\mathrm{Ld}$ & $20+39$ & $\mathrm{Ld}$ & + & nd \\
\hline Lp 02 & + & Lesion & $L(L$.$) mexicana$ & $\mathrm{Lm}, \mathrm{Tc} \operatorname{cl} 20$ & $\mathrm{Lm}$ & 39 & $\mathrm{Lm}$ & nd & nd \\
\hline Chu 04 & - & Blood & $\mathrm{Tc}$ cl $20+39$ & $\mathrm{Lm}, \mathrm{Tc} \operatorname{cl} 20+39$ & $\mathrm{Lm}$ & $20+39$ & $\mathrm{Lb}$ & + & + \\
\hline Lp 07 & + & Lesion & $\begin{array}{l}L .(V .) \text { braziliensis, } \\
L .(L .) \text { mexicana }\end{array}$ & Lb, Lm, Tc cl 39 & $\mathrm{Lm}$ & PCR (-) & $\mathrm{Lb}$ & nd & nd \\
\hline Lp 06 & + & Lesion & L. (V.) braziliensis, Tc cl 39 & $\mathrm{Lb}, \mathrm{Tc} \operatorname{cl} 39$ & $\mathrm{Lb}$ & $20+39$ & $\mathrm{Lb}$ & + & nd \\
\hline Chu 02 & - & Blood & L. (L.) mexicana, $\mathrm{Tc} \mathrm{cl} 20$ & Lm, Tc cl $20+39$ & $\mathrm{Lm}$ & $20+39$ & $\mathrm{Lm}$ & + & + \\
\hline Chu 33 & - & 1 & / & / & $\mathrm{Lb}$ & other clone ${ }^{a}$ & $\mathrm{Lb}$ & + & + \\
\hline Chu 16 & nd & / & l & l & $\mathrm{Lm}$ & $20+39$ & PCR (-) & - & - \\
\hline Lp 22 & nd & l & l & l & $\mathrm{Ld}$ & PCR (-) & $\mathrm{Lm}$ & + & nd \\
\hline Lp 23 & + & l & l & l & $\mathrm{Ld}$ & PCR (-) & $\mathrm{Lm}$ & + & - \\
\hline Lp 21 & - & I & I & I & $\mathrm{Ld}$ & 39 & $\mathrm{Ld}$ & - & nd \\
\hline Chu 24 & - & I & I & I & $\mathrm{Lm}$ & $20+39$ & $\mathrm{Lb}$ & + & + \\
\hline Chu 40 & - & I & I & I & $\mathrm{Lm}$ & 39 & Hyb. (-) & + & + \\
\hline Chu 41 & - & I & I & l & $\mathrm{Lm}$ & 39 & Hyb. (-) & + & + \\
\hline Chu 27 & - & I & I & l & $\mathrm{Lm}$ & 39 & $\mathrm{Lm}$ & + & + \\
\hline Chu 28 & - & l & I & l & $\mathrm{Lm}$ & 20 & Hyb. (-) & - & + \\
\hline Lp 12 & - & l & l & l & $\mathrm{Lm}$ & other clone $^{a}$ & PCR (-) & nd & - \\
\hline Lp 40 & + & I & l & I & $\mathrm{Lb}, \mathrm{Lm}$ & PCR (-) & $\mathrm{Lb}$ & nd & - \\
\hline Chu 37 & - & l & l & l & $\mathrm{Lm}, \mathrm{Ld}$ & PCR (-) & Hyb. (-) & + & - \\
\hline Chu 45 & - & I & l & l & Hyb. (-) & PCR (-) & $\mathrm{Lb}, \mathrm{Lm}$ & - & - \\
\hline Lp 08 & - & I & 1 & I & Hyb. (-) & $20+39$ & $\mathrm{Lb}$ & nd & - \\
\hline Lp 44 & nd & 1 & I & I & Hyb. (-) & PCR (-) & $\mathrm{Lm}, \mathrm{Ld}$ & nd & nd \\
\hline Chu 21 & - & 1 & I & I & PCR (-) & $20+39$ & $\mathrm{Lb}, \mathrm{Lm}$ & - & - \\
\hline
\end{tabular}

I: absence of data because the cultures were negative; Tc: Trypanosoma cruzi ; cl: clone; Lb, Lm and Ld: L. braziliensis, L. donovani, and L. mexicana complexes respectively; Hyb: hybridization; $a$ : the PCR was positive but hybridizations with clone 20 and clone 39 probes were negative; nd: not done. 
a major $330 \mathrm{bp}$ fragment specific of $T$. cruzi was obtained. The specificity of the five probes is shown in the right part of the figure. On the left part of the figure examples of hybridization patterns are shown evidencing, in a single patient, mixed infections by Leishmania spp. (lanes 8 and 9), by two Leishmania strains and T. cruzi clone 20 and 39 (lane 1, 2, 3; lane 6, 10, 13) by one Leishmania strain and $T$. cruzi clone 39 (lane 15, 16) and T. cruzi clone 20 (lane 7, 14) and by one Leishmania strain and T. cruzi clones 20 and 39 (lane 4, 5; lane 11, 12).

Surprisingly, in some cases any probe recognised PCR products amplified by L1-L2 primers from some blood and lesion samples since a multi banding pattern was obtained by PCR (Table). Further study of a large sample (117 samples) of normal blood shown that PCR products should be obtained in $10 \%$ of the cases but any hybridization with the three Leishmania complex species was observed (data no shown).

The Table summarizes the results of the PCR-hybridization. Leishmania spp. was identified in blood and/or lesions of the 29 studied patients confirming Leishmania infections. L. mexicana and L. braziliensis complexes species were detected in the majority of the patients $(69 \%$ and $51.7 \%$ respectively). L. braziliensis was more frequently detected in lesion than in blood $(41.3 \%$ and $10.3 \%$ respectively) while inverse result was observed for $L$. mexicana (48.3\% in blood and $31 \%$ in lesions). L. donovani complex was detected in the blood and the lesion of the patient with visceral leishmaniasis (Lp 17) and in five others $(20.7 \%)$, three cases in blood, one case in lesion, and one case in blood and lesion.

Among the 29 patients, eight $(27.6 \%)$ showed a mixed infection with Leishmania spp., 17 (58.6\%) a mixed infections with Leishmania and T. cruzi, and four (13.8\%) a multi infections of Leishmania associate with T. cruzi infection (clones 20 and 39). The presence of T. cruzi was detected in 21 patients $(72.4 \%)$ from blood and in two other patients from the strain isolated from the lesions (Lp 07, Lp 46). The percentage of Leishmania-T. cruzi infections together reaches $79.3 \%$ of the patients. The identification of $T$. cruzi clones confirms earlier work indicating the importance of major clones 20 and 39 in patients, however highest frequency was found for mixed infections by the two clones (52.4\%). In two cases (Lp 12 and Chu 33) T. cruzi PCR products amplified from blood samples were not recognised by either probes clone 20 nor clone 39 . These cases previously reported represent infections by other clones whose taxonomic status remains to be determined.

Serological analysis - IgM antibodies against promastigote forms of $L$. (V.) braziliensis (IF test) and IgG antibodies against total aqueous soluble protein extract of T. cruzi (ELISA) were detected together on 15 patient sera (Table). Seven sera (50\%) were positive in both tests, which would confirm mixed infections of Leishmania and T. cruzi. Three sera were negative in both tests, four others were IF positive and ELISA negative and only one sera was IF negative and ELISA positive. PCR/hybridization applied on the same patient group, showed a mixed infection for 11 patients (73.3\%). No relationship between antibody patterns and parasite species was observed.

\section{DISCUSSION}

Isolation and characterization of parasite isolated from patients remain the convincing method to demonstrate mixed infections of Leishmania-T. cruzi. In the present study we have prevailed a low percentage of parasite isolation in culture and the use of Schneider medium most

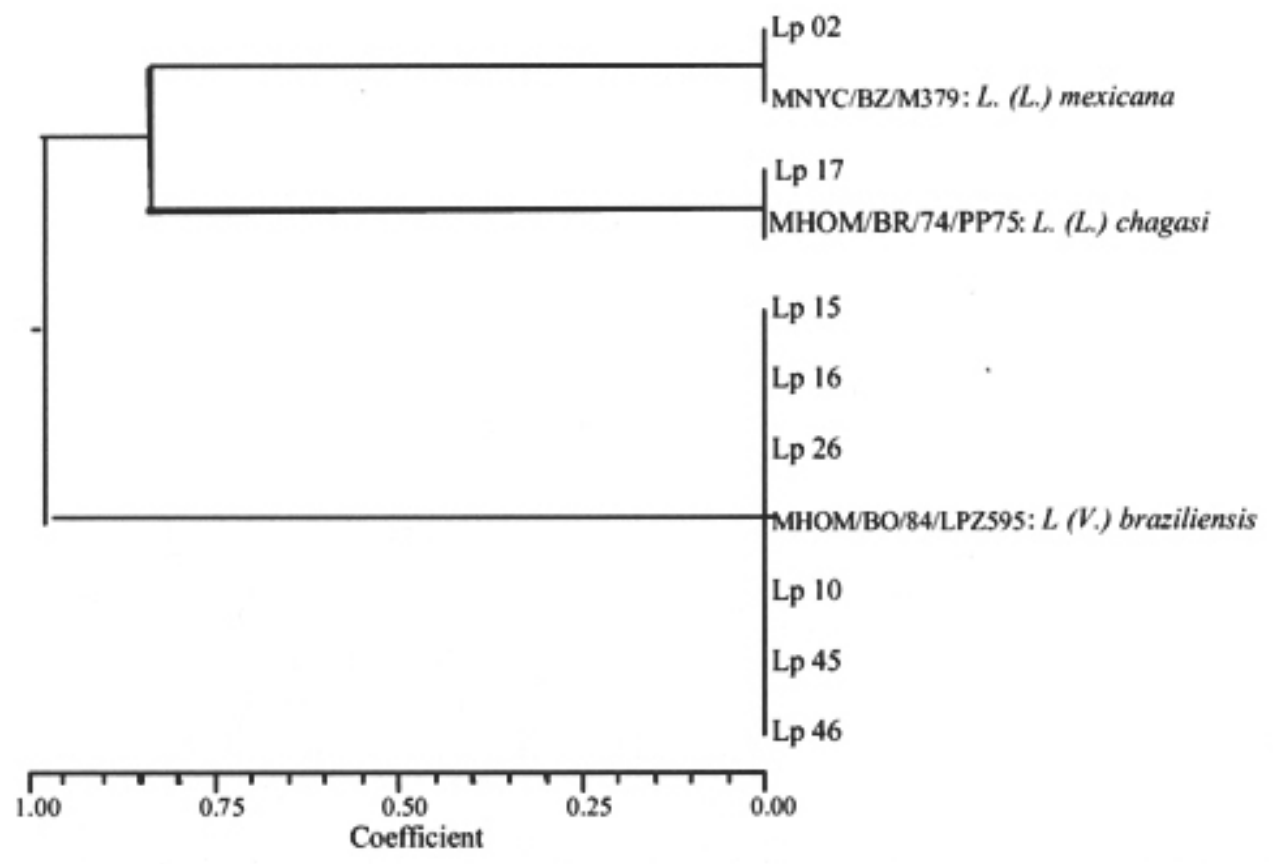

Fig 2: unweighted Pair Group Method with arithmetic averages dendrogram built from Jaccard's genetic distance based on the analysis of 11 isoenzymatic loci. References stocks of Leishmania: L. (L.) mexicana (MNYC/BZ/M379), L. (L.) chagasi (MHOM/BR/74/PP75), L. (V.) braziliensis (MHOM/BO/84/LPZ595). The strains were isolated from the corresponding code of the patient in Table. 


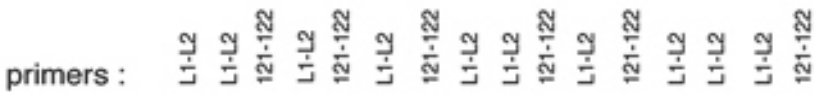

$$
\begin{aligned}
& \begin{array}{lllllllllllllllll}
1 & 2 & 3 & 4 & 5 & 6 & 7 & 8 & 9 & 10 & 11 & 12 & 13 & 14 & 15 & 16 & 17
\end{array}
\end{aligned}
$$

a)

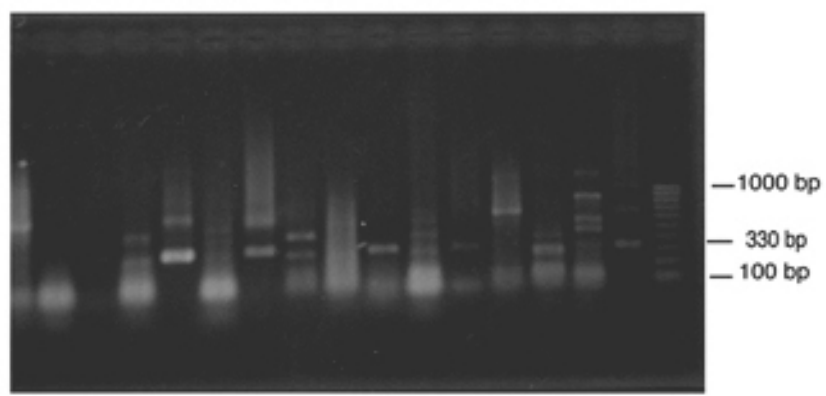

$\begin{array}{lllllllllllllllll}1 & 2 & 3 & 4 & 5 & 6 & 7 & 8 & 9 & 10 & 11 & 12 & 13 & 14 & 15 & 16 & 17\end{array}$

L.(V.) brasiliensis probe

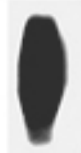

$\begin{array}{lllllllllllllllll}1 & 2 & 3 & 4 & 5 & 6 & 7 & 8 & 9 & 10 & 11 & 12 & 13 & 14 & 15 & 16 & 17\end{array}$

L. (L.) mexicana probe
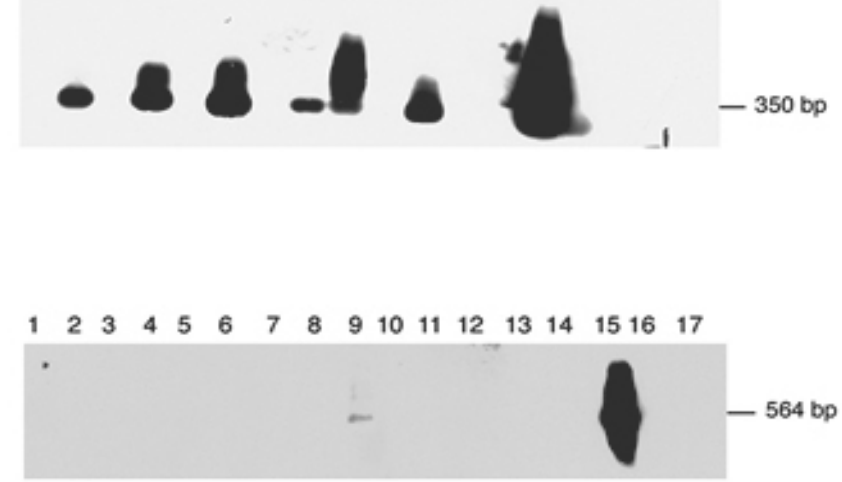

L. (L.) chagasi probe

T. cruzi (clone 39) probe
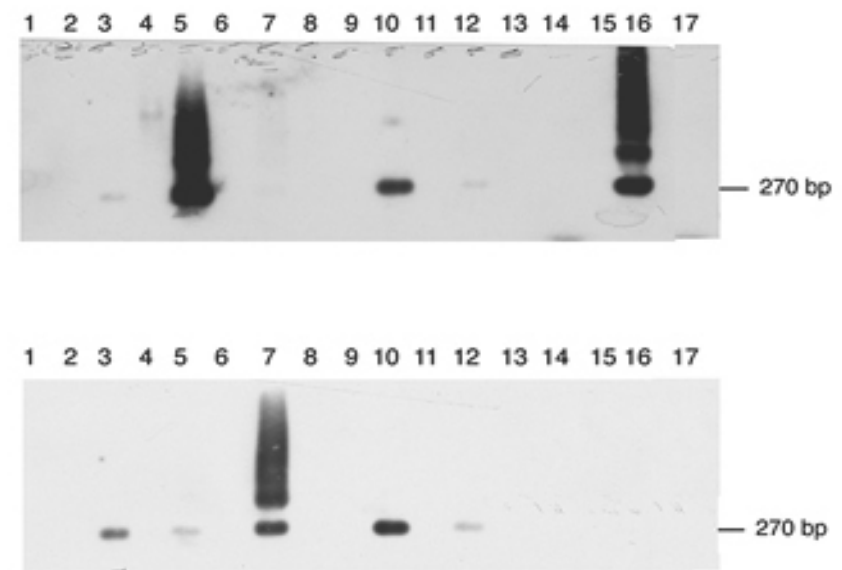
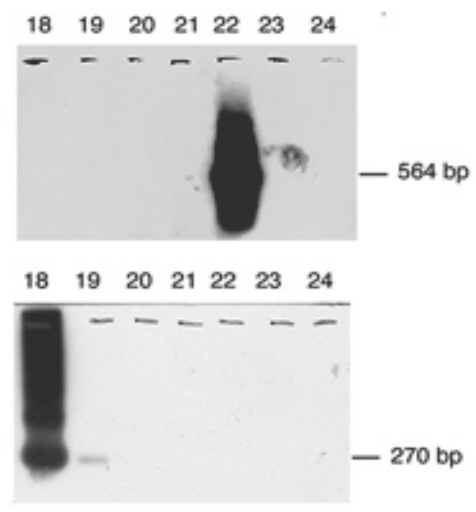

\section{reference strains}

$\begin{array}{lllllll}18 & 19 & 20 & 21 & 22 & 23 & 24\end{array}$
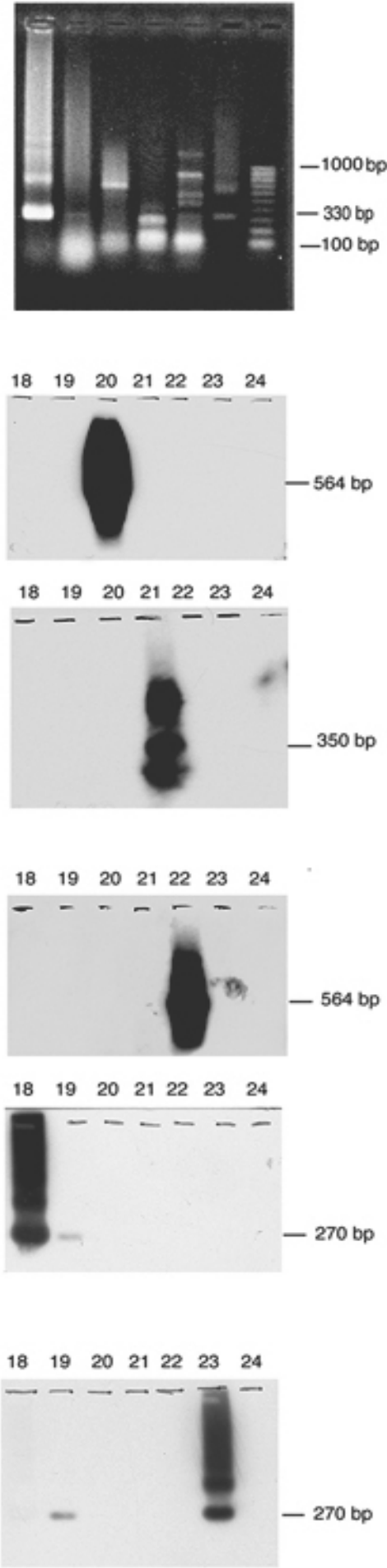

Fig 3a: ethidium bromide stained 1.5\% agarose gel containing kDNA PCR products from Trypanosoma cruzi (330 bp) and Leishmania spp. (100 to 1300 bp). Lanes - 1-3: patient chu 24, lesion: primer L1-L2, blood: primer L1-L2, blood: primer 121-122; 4-5: patient chu 02, blood culture: primer L1-L2, primer 121-122; 6, 10, 13: patient Lp 16, blood: primer L1-L2, blood: primer 121-122, lesion: primer L1L2; 7, 14: patient chu 28, blood: primer 121-122, blood: primer L1-L2; 8: patient Lp 40, blood: primer L1-L2; 9: patient chu 37, blood: primer L1-L2; 11-12: patient chu 16, blood: primer L1-L2 and 121-122; 15-16: patient Lp 21, blood primer L1-L2, blood primer 121122; 18-23: reference strains, respectively: T. cruzi: TPK1 clone 39; T. cruzi: mixed of TPK1 clone 39 and SO34 cl4 clone 20; L. (V.) braziliensis (MHOM/BO/84/LPZ595); L. (L.) mexicana (MNYC/BZ/M379); L. (L.) chagasi (MHOM/BR/74/PP75); T. cruzi : SO34 cl 4: clone 20; 17, 24: PCR low Ladder, 100 bp. Hybridizations with $L$. (V.) braziliensis probe (MHOM/BO/84/LPZ595); L. (L.) mexicana probe (MNYC/BZ/M379); L (L.). chagasi probe (MHOM/BR/74/PP75); T. cruzi clone 39 probe (TPK1); T. cruzi clone 20 probe (SO34 cl 4) 
likely favoured the isolation of Leishmania over T. cruzi. Moreover, the percentage of positive cultures from primary skin lesions and mucosal tissues is generally very low due to contamination problems in cultures and the troubles to obtain adequate biopsies. The sampling of isolated strains is probably also biased through the selection that occurs during the culture step (Ibrahim et al. 1994, Bosseno et al. 2000). Even though the isoenzyme analysis remains the basic approach for species characterization, the current results of PCR/hybridization applied to parasite isolates increase the sensitivity, which enables to detect in a few steps multi species infections.

In the framework of the MLEE data, the profiles interrelated to mixed infection could be questioned. The two bands pattern should be equated to an heterozygous state for a monomeric enzyme in a diploid organism (hybrid) or to a double pattern for two different strains with homozygous states. Hybrids between Leishmania parasites have already been observed based on phenotypic and genotypic characteristics (Darce et al. 1991, Belli et al. 1994, Dujardin et al. 1995, Noyes et al. 1996, Bañuls et al. 1997) and similarly scarce events of hybridization in $T$. cruzi have been reported (Bogliolo et al. 1996, Carrasco et al. 1996, Brisse et al. 1998). Nevertheless, in both cases the frequency of genetic exchange in natural populations seems to be very low. In the current work, the high percentage of mixed infections of Leishmania sp. and T. cruziLeishmania sp. observed by PCR/hybridization support our interpretation. The PCR/hybridization confirmed the MLEE characterization of the strains but detected additional species. As expected, the PCR is more sensitive; experimental T. cruzi mixture of different clones showed that MLEE analysis revealed mixtures of at least $10 \%$ with only part of the enzyme systems (unpublished data) while Bosseno et al. (2000) reported that to detect mixture in culture, the PCR/hybridization is three times more sensitive that isoenzyme characterization.

One strain (Lp 02) had a MLEE profile identical to the $L$. (L.) mexicana reference strain. Moreover, two diagnostic loci (Nhi and Pgm) between $L(L$.) amazonensis and $L$. (L.) mexicana previously identified by Bañuls (1998) clearly characterized this isolate as belonging to $L$. (L.) mexicana (data not shown). This species had never been identified in Bolivia but it has been characterized in patients, dogs and vectors in an Andean region of Ecuador where cutaneous leishmaniasis is highly endemic (Hashiguchi et al. 1991). Nevertheless, further studies are necessary to confirm the presence of this species in the Andean part of Bolivia.

The direct identification of simultaneous infections using PCR/hybridization applied to blood and lesions surely presented a large advantage over culture typing due to the high sensitivity of the PCR. Nonetheless, processing large samples of blood and lesions with the primers L1 and L2, we questioned the specificity of these primers; PCR products were obtained from $10 \%$ of normal blood but their hybridization remain negative with the different Leishmania complex probes. Sequences homologies of L1 and L2 primers were then found in a human DNA bank and can explain this cross reactivity. Consequently, the hybridization step is indispensable for the detection and characterization of the Leishmania as done for all the studied samples. Several discrepancies of Leishmania species identification were noted in blood and lesion of the same patient. Furthermore, parasites belonging to $L$. braziliensis and L. mexicana complexes were unequally detected in lesions and bloods. This result could be explained by the higher ability of the current strains of $L$. mexicana complex to reach the circulation, given that the PCR sensibility evaluated by the addition of DNA from $L$. (V.) braziliensis, $L$. (L.) mexicana reference strains, was similar in blood and lesion but more sensitive to $L$. braziliensis complexes than to L. mexicana $(0.1 \mathrm{pg}$ and 10 pg respectively) (Mita 1999).

Leishmania spp. and T. cruzi exhibit antigenic crossreactivity (Manson-Bahr 1987, Chiller et al. 1990) and the serological tests used for these diagnosis (IFA, IHA, ELISA) may lead to confuse epidemiological data and prevent specific diagnosis and treatment. The present data showed that the seven cases with positive serology for leishmaniasis and Chagas disease were actually infected by both parasites. All the same, among the other patients, which were infected with Leishmania spp., seven of them had undetectable $\operatorname{IgM}$ antibodies against Leishmania. Among the 15 patients with T. cruzi concurrent infection detected by PCR/hybridization in blood, seven of them showed a negative serology with T. cruzi ELISA. No data indicated that an infection with either parasites induced a protective immunity against the other (Chiller et al. 1990, Chiaramonte et al. 1996) but the present serological results demonstrated that a disorder of specific humoral response can be observed in mixed infections.

Owing to this approach the epidemiological facies in the Sub-Andean region appears much more complex than previously reported. In the Yungas valley, $L$. (V.) braziliensis was considered as the agent of cutaneous leishmaniasis (Desjeux et al. 1987). The PCR-hybridization showed the co-existence of three Leishmania species complex, and a separated distribution of L. mexicana and L. braziliensis complexes in Bolivia is no longer accurate. The patients infected by $L$. mexicana complex (69\%) had been possibly infected in other endemic areas but a specimen of Lutzomyia nuneztovari anglesi (Diptera: Psychdidae) collected in the studied area and naturally infected by $L$. (V.) braziliensis (Torrez et al. 1998), was found positive by PCR-hybridization with both probes $L$. (V.) braziliensis and $L$. (L.) mexicana (data not shown). L. nuneztovari anglesi is a candidate vector of the cutaneous and muco cutaneous leishmaniasis in the Yungas valleys and a study in process in our laboratory using PCR/hybridization identification revealed that species of $L$. braziliensis and $L$. mexicana complexes share the same putative reservoir. Herein, visceral cases are not an exception, the declared case of a visceral leishmaniasis concerned a 2 -year-old child and the other five infected patients were both children (5, 12 and 15 years old) and adults (29 and 52 years old) who were all healthy people. Obviously, the rate of visceral leishmaniasis is probably underestimated in Bolivia due to the difficulties in reaching correct diagnosis and the scarcity of available prevalence studies. The symptoms of visceral leishmaniasis can be clinically identifiable but some cases are asympomatic or pociasymptomatic and the illness is 
often indistinguishable from other infectious diseases including Chagas disease.

Concurrent infection with two species of Leishmania parasites occurs in $41 \%$ of the patients and this implies careful attention to the treatment. The clinical manifestations of Leishmania infection in humans are largely dependent on the immune responsiveness of the host and the virulence of the infecting parasite strain which explains differences in therapeutical responses (Melby et al. 1992, Grimaldi \& Tesh 1993). In some cases of simultaneous natural infection, patients are reported to require distinct treatments (Al-Diwany et al. 1995) or to not respond to the treatment (Rassam et al. 1993).

Chagas disease is widespread in Bolivia and the Yungas valley are not spared. Nevertheless, this area is considered as a low endemic region in Bolivia although $T$. cruzi infected $79.3 \%$ of the current Leishmania patients. Part of the patients could have been infected in other high endemic areas of the country but this high rate of mixed infection could be also explained by higher susceptibility of chagasic patients to Leishmania infection. In such cases of mixed infections, sudden death as a result of chagasic cardiopathy during the pentavalent antimonial therapy and electrocardiograph changes during the course of the leishmaniasis treatment (meglumine antimoniaque, sodium stiboglucanate) have been observed (Chulay et al. 1985, Sampaio et al. 1988, Antezana et al. 1992). However, antimonial therapy effects in chronic chagasic cardiopathy are not well established. Therefore, chagas infection should be systematically searched for in leishmaniasis patients and antimonial therapy needs to be followed-up by an electrocardiogram.

Among the studied leishmaniasis patients, a high percentage (52.4\%) of double infection with clones 20 and 39 was observed. Previous work showed, in Bolivia, similar frequencies of clones 20 and 39 and high rate of mixtures in vectors and during the acute phase of Chagas disease (Brenière et al. 1998) but, in later infection stages, higher prevalence of $T$. cruzi clone 39 over clone 20 in blood was observed with only $11.1 \%$ of double infections (clones 20 and 39) (Brenière et al. 2002). These results have been related to biological differences between the clones as virulence and variable susceptibility of the clones to the immune response (control of parasitemia) developed after the acute phase of human infection. By tricking the immune defences of the host, multi-species infections may increase the parasite's chances of transmission and could play a specific role in the pathogenecity of the disease (Tibayrenc 1999). Obviously, the schedule of Leishmania and T. cruzi infections on the studied patients is unknown and the follow up of patients with leishmaniasis or Chagas disease living in overlapping endemic areas is necessary in order to reach a better understanding of the interactions between the two parasites when the second infection occurs.

\section{ACKNOWLEDGEMENTS}

To Dr Eddy Martinez for allowing us to process a bonemarrow puncture on a child from the Children's Hospital in La Paz and to Marie José Tirard for English corrections.

\section{REFERENCES}

Al-Diwany LJ, Al-Awkati, NA, Aita M, Rassam, MB 1995. Concomitant natural infection with $L$. donovani and $L$. major: a case report from Iraq. Sozial-und-Praventivmedizin 40: 234-238.

Antezana G, Zeballos R, Mendoza C, Lyevre P, Valda L, Cardenas F, Noriega H, Ugarta H, Dedet P 1992. Electrocardiographic alterations during treatment of mucocutaneous leishmaniasis with meglumine antimoniate and allopurinol. Trans $R$ Soc Trop Med Hyg 86: 31-33.

Bañuls AL 1998. Apport de la Génétique Evolutive à l'Epidémiologie et à la Taxonomie du Genre Leishmania, PHD Thesis, Université des Sciences et Techniques du Languedoc, Montpellier, France, 196 pp.

Bañuls AL, Guerrini F, Le Pont F, Barrera C, Espinel I, Guderian R, Echeverria R, Tibayrenc M 1997. Evidence for hybridization by multilocus enzyme electrophoresis and random amplified polymorphic DNA between Leishmania braziliensis and Leishmania panamensis/guyanensis in Ecuador. J Euk Microbiol 44: 408-411.

Bastrenta B, Mita N, Flores M, Buitrago R, Vargas F, Le Pont F, Torrez M, Brenière SF 2002. First evidence of transmission of Leishmania (Viannia) lainsoni in a Sub Andean region of Bolivia. Acta Trop 83: 249-253.

Belli AA, Miles MA, Kelly JM 1994. A putative Leishmania panamensis/Leishmania braziliensis hybrid is a causative agent of human cutaneous leishmaniasis in Nicaragua. Parasitology 109: 435-442.

Ben Abderrazak S, Guerrini F, Mathieu-Daudé F, Truc P, Neubauer K, Lewicka K, Barnabé C, Tibayrenc M 1993. Isoenzyme electrophoresis for parasite characterization. In JE Hyde, Methods in Molecular Biology, Human Press, New York, p. 361-382.

Bogliolo AR, Lauria-Pires L, Gibson WC 1996. Polymorphisms in Trypanosoma cruzi: evidence of genetic recombination. Acta Trop 61: 31-40.

Bosseno MF, Yacsik N, Vargas F, Brenière SF 2000. Selection of Trypanosoma cruzi clonal genotypes (clonet 20 and 39) isolated from Bolivian triatomines following subculture in liquid medium. Mem Inst Oswaldo Cruz 95: 601-607.

Brenière SF, Bosseno MF, Noireau F, Yacsik N, Liegeard P, Aznar C, Hontebeyrie M 2002. Integrate study of a Bolivian population infected by Trypanosoma cruzi, the agent of Chagas disease. Mem Inst Oswaldo Cruz 97: 289-295.

Brenière SF, Bosseno MF, Telleria J, Bastrenta B, Yacsik N, Noireau F, Alcazar JL, Barnabé C, Wincker P, Tibayrenc M 1998. Different behaviour of two Trypanosoma cruzi major clones: transmission and circulation in Bolivian young patients. Exp Parasitol 89: 285-296.

Brenière SF, Bosseno MF, Telleria J, Carrasco R, Vargas F, Yaksic N, Noireau F 1995. Field application of PCR diagnosis and strain typing of Trypanosoma cruzi in Bolivian triatomines. Am J Trop Med Hyg 53: 179-184.

Brenière SF, Carrasco R, Miguez H, Lemesre JL, Carlier Y 1985. Comparisons of immunological tests for serodiagnosis of Chagas disease in Bolivia. Trop Geogr Med 37: 231-238.

Brenière SF, Telleria J, Bosseno MF, Buitrago R, Bastrenta B, Cuny G, Bañuls AL, Brewster S, Barker DC 1999. Polymerase chain reaction-based identification of new World Leishmania species complexes by specific kDNA probes. Acta Trop 73: 283-293.

Brisse S, Barnabé C, Bañuls AL, Sidibé I, Noël S, Tibayrenc M. 1998. A phylogenetic analysis of the Trypanosoma cruzi genome project CL-Brener reference strain by multilocus enzyme electrophoresis and multiprimer random amplified polymorphic DNA fingerprinting. Mol 
Biochem Parasitol 92: 253-263

Britto C, Cardoso MA, Wincker P, Morel CM 1993. A simple protocol for the physical cleavage of Trypanosoma cruzi kinetoplast DNA present in blood samples and its use in polymerase chain reaction (PCR)-based diagnosis of chronic Chagas disease. Mem Inst Oswoldo Cruz 88: 171-172.

Bryan RT, Tonn RS 1990. Bolivia: Current Status and Potential Development of Control Strategy of Chagas Disease, Rapp USAID/VBC, Arlington, VA, $60 \mathrm{pp}$.

Camargo ME 1966. Fluorescent antibody test for the serodiagnosis of American trypanosomiasis. Technical modification employing preserved culture forms of Trypanososma cruzi in a slide test. Rev Inst Med Trop São Paulo 8: 227234.

Carrasco HJ, Frame IA, Valente SA, Miles MA 1996. Genetic exchange as a possible source of genomic diversity in sylvatic populations of Trypanosoma cruzi. Am J Trop Med Hyg 54: 418-24.

Chiaramonte MG, Zwirner NW, Caropresi SL, Taranto NJ, Malchiodi EL 1996. Trypanosoma cruzi and Leishmania spp. human mixed infection. Am J Trop Med Hyg 54: 271273.

Chiller TM, Samudio MA, Zoulek G 1990. IgG antibody reactivity with Trypanosoma cruzi and Leishmania antigens in sera of patients with Chagas' disease and leishmaniasis. Am J Trop Med Hyg 22: 696-698.

Chulay JD, Spencer HC, Mugambi M 1985. Electrocardiographic changes during treatment of leishmaniasis with pentavalent antimony (sodium stibogluconate). Am J Trop Med Hyg 34: 702-709.

Darce M, Moran J, Palacios X, Belli AA, Gomez-Urcuyo F, Zamora D, Valle S, Gantier JC, Momen H, Grimaldi G 1991. Etiology of human cutaneous leishmaniasis in Nicaragua. Trans $R$ Soc Trop Med Hyg 85: 58-59.

Dedet JP 1993. Leishmania et leishmaniose du continent américain. Ann Inst Pasteur Actualités 4: 3-25.

Desjeux P, Le pont F, Mollinedo S, Tybayrenc M 1986. Les Leishmania de Bolivie II. Leishmania chagasi Cunha et Chagas, 1937. Premiers isolement dans les "Yungas" du département de la Paz. Comparaison isoenzymatique de souches de l'homme du chien et du phlébotome Lutzomyia longipalpis (Luts et Neiva, 1912). In JA Rioux, Leishmania. Taxonomie et Phylogénèse, Institut Méditerranéen d'Etudes Epidémiologiques et Ecologiques, Montpellier, p. 411-419.

Desjeux P, Mollinedo S, Le Pont F, Paredes A, Urgate G 1987. Cutaneous leishmaniasis in Bolivia. A study of 185 cases from Alto Beni (La Paz Department). Isolation and isoenzyme characterization of 26 strains of Leishmania braziliensis braziliensis. Trans $R$ Soc Trop Med Hyg 81: 742-746.

Desjeux P, Quilici M, Lapierre J 1974. A propos de 113 cas de leishmanioses cutanées et cutanéo-muqueuse observés en Bolive. Etude séro-immunologiques de 71 cas. Bull Soc Pathol Exot 67: 387-395.

Dimier-David L, Inofuentes A, Carrasco M, David C, Vargas F, Revollo S, Dedet JP 1991. Nouveau cas autochtone de leishmaniose viscérale en Bolivie. Ann Soc Belge Méd Trop 71: 275-278.

Dujardin JC, Bañuls Al, Llanos-Cuentas A, Alvarez E, Dedonker S, Jacquet D, Le Ray D, Arevalo J, Tibayrenc M 1995. Putative Leishmania hybrids in the Eastern Andean valley of Huanuco, Peru. Acta Trop 58: 293-307.

Grimaldi G, Tesh RB 1993. Leishmaniasis of the New World: current concepts and implications for future research. Clin Microbiol Rev 6: 230-250.
Hashiguchi Y, Gomez EA, de Coronel VV, Mimori T, Kawabata M, Furuya M, Nonaka S, Takaoka H, Alexander JB, Quizhpe AM 1991. Andean leishmaniasis in Ecuador caused by infection with Leishmania mexicana and L. major-like parasites. Am J Trop Med Hyg 44: 205-217.

Hernandez-Montes O, Monroy-Ostria A, McCann S, Barker DC 1998. Identification of Mexican Leishmania species by analysis of PCR amplified DNA. Acta Trop 71: 139-153.

Ibrahim ME, Smyth AJ, Ali MH, Barker DC, Kharazmi A 1994. Polymerase chain reaction can reveal the occurrence of naturally mixed infections with Leishmania parasites. Acta Trop 57: 327-332.

Jaccard P 1908. Nouvelles recherches sur la distribution florale. Bull Soc Vaud Sc Na 44: 223-270.

Lemesre JL, Afchain D, Orozco O, Loyens M, Brenière FS, Desjeux P, Carlier Y, Martin U, Nogueira-Queiroz JA, le Ray D, Capron A 1986. Specific and sensitive immunological diagnosis of Chagas' disease by competitive antibody enzyme immunoassay using a Trypanosoma cruzi specific monoclonal antibody. Am J Trop Med Hyg 35: 86-93.

Le Pont F, Desjeux P, Torrez-Espejo JM, Fournet A, Mouchet J 1992. Leishmanioses et Phlebotomes de Bolivie, ORSTOM and INSERM, Paris, 116 pp.

Manson-Bahr PC 1987. Diagnosis. In W Peters, R KillickKendrick (eds), The Leishmaniases. Biology and Medecine, Vol. II, Academic Press, London, p. 703-729.

Martinez E, Le Pont F, Mollinedo S, Cupolillo E 2001. A first case of cutaneous leishmaniasis due to Leishmania (Viannia) lainsoni in Bolivia. Trans R Soc Trop Med Hyg 95: 375-377.

Martinez E, Le Pont F, Torrez M, Telleria J, Vargas F, Muñoz M, De Doncker S, Dujardin JC, Dujardin JP 1998. A new focus of cutaneous leishmaniasis due to Leishmania amazonensis in a Sub Andean region of Bolivia. Acta Trop 71: 97-106.

Melby PC, Kreutzer RD, McMahon-Pratt D, Gam AA, Neva FA 1992. Cutaneous leishmaniasis: review of 59 cases seen at the National Institutes of Health. Clin Infect Dis 15: 924937.

Mita N 1999. Infecciones Mixtas: Identificación de Complejos de Leishmania y Clones de Trypanosoma cruzi por PCRHibridación en Pacientes y Mamíferos Peridomiciliares, Thesis, Universidad Mayor de San Andrès, La Paz, Bolivia, $168 \mathrm{pp}$.

Noyes HA, Belli AA, Maingon R 1996. Appraisal of various random amplified polymorphic DNA-polymerase chain reaction primers for Leishmania identification. Am J Trop Med Hyg 55: 98-105.

Oliveira Neto MP, Marzochi MCA, Grimaldi G, Pacheco RS, Toledo LM, Momen H 1985. Concurrent human infection with Leishmania donovani and Leishmania braziliensis braziliensis. Ann Trop Med Parasitol 80: 587-592.

Pless M, Juranck D, Kosarsky P, Steurer F, Tapia G, Bermudez H 1992. The epidemiology of Chagas' disease in a hyperendemic area of Cochabamba, Bolivia: a clinical study including electrocardiography, seroreactivity to Trypanosoma cruzi, xenodiagnosis and domiciliary triatomine distribution. Am J Trop Med Hyg 47: 539-546.

Rassam MB, Atia MM, Al-Diwany LJ, Al-Awkati NA 1993. Simultaneous natural infection with three human Leishmania species. J Protozool Res 3: 81-88.

Sampaio RNR, Netto EM, Faria EA, Sampaio JHD, Freitas LCF, Marsden PD 1988. Morte súbita causada por glucantime. An Bras Derm 63: 35-37.

Silveira FT, Lainson R, Shaw JJ, Ribeiro R 1984. Cutaneous leishmaniasis in Amazonia. Report of the 1st human case of mixed infection, determined by 2 different Leishmania species: Leishmania brasiliensis and Leishmania mexicana 
amazonensis. Rev Inst Med Trop São Paulo 26: 272-275.

Sokal RR, Sneath PHA 1963. Principles of Numerical Taxonomy, Freeman and Company, San Francisco, 359 pp.

Tibayrenc M 1999. Towards an integrated genetic epidemiology of parasitic protozoa and other pathogens. Annu Rev Genet 33: 449-477.

Tibayrenc M, Ward P, Moya A, Ayala F 1986. Natural populations of Trypanosoma cruzi, the agent of Chagas' disease, have a complex multiclonal structure. Proc Nat Acad Sci USA 83: 115-119.

Torrez M, Lopez M, Le Pont F, Martinez E, Muñoz M, Hervas
D, Yaksic N, Arevalo J, Sossa D, Dedet JP, Dujardin JP 1998. Lutzomyia nuneztovari anglesi (Diptera: Psychodidae) as a probable vector of Leishmania braziliensis in the Yungas, Bolivia. Acta Trop 71: 311-316.

WHO-World Health Organization 1991. Control of Chagas Disease, WHO Tech Report 811, 95 pp.

Wincker P, Britto C, Borges Pereira J, Cardoso MA, Oelemann W, Morel CM 1994. Use of a simplified polymerase chain reaction procedure to detect Trypanosoma cruzi in blood samples from chronic chagasic patients in a rural endemic area. Am J Trop Med Hyg 51: 171-177. 